\title{
Investigation and Evaluation of Product-Supplier's Company
}

\author{
Huaping Chen \\ Xi'an Polytechnic University, Xi'an 710048, China \\ Tel: 86-29-8233-0059 E-mail:chenhuaping7024@163.com
}

\begin{abstract}
In the process of selecting the satisfactory product-suppliers the buyer should investigate and evaluate the candidates by recognizing the situation of the supplier's companies. The buyer should pay attention to the factors such as the suppliers' certificates and documents, the situation of manufacturing facilities and other hardware, technical performance and quality assurance, company's financial situation, organization and the management of human resources, ability to storage, transport and supply of products, management ability and team cooperation, company's environment, social responsibility and ability in sustainable development and historical records.
\end{abstract}

Keywords: Buyer, Product-supplier

In order to select the satisfactory product suppliers one of the prerequisites is to investigate and evaluate the candidates thoroughly and the in situ survey of the suppliers' companies is especially vital. According to the scale and the capital situation of the suppliers' companies the buyer needs to select 2-3 candidates as the survey targets.

A complete plan for the survey is essential for recognizing the supplier's situation in operation, capability and their status. The survey results for the suppliers' products quality, manufacturing capability, product delivery, product price and operation goal will affect the buyers' final decision. In addition to these there are other more important factors which include companies' historical operation record, production facility, technical level, financial situation, management, market reputation, program flexibility, communication situation, labor-management relationship, companies' location and their behaviors in social responsibility.

The buyer usually organizes a cross-functional team to perform the survey and the team consists of the staffs in supplying management, material management, engineering devise, manufacturing management, quality management and financial management. The survey can be in the forms such as discussion, documents reading, evaluation of the manufacturing facilities, functional branches visiting and the random discussion with the companies' staffs.

The following are the main factors considered during the survey:

\section{Checking the Suppliers' Certificates and Documents}

These certificates and documents mainly include the manufacturing license, operation qualification, enterprise legal certificate, product quality confirmation, award certificates and the brief introduction of the enterprise, which includes the operation category, brief history and the sales. The company documents related to finance, human resource management, manufacturing process management and the details of the current customers should also be investigated in order to meet the requirements in the following cooperation. The suppliers should be responsible for the actuality of these documents.

\section{The Situation of Manufacturing Facilities and Other Hardware}

These include the information such as workshop area and the arrangement, manufacturing facilities and the functional properties, the productivity for meeting the requirement of the customers' orders and the installation of the manufacturing facilities for production expanding or further modification.

\section{Assessment of Technical Performance and Quality Assurance}

The most important subject in the survey is to assess the company's technical performance. Through this assessment the buyer can recognize the supplier's ability for meeting the buyer's long-and-short requirement, whether the supplier can meet the buyer's lowest needs and the requirement in product function. In this process the supplier's superiority in product quality, the post-service situation, technical innovation, ability in product supplying and quality assurance system should also be considered. Normally the technicians, designers and the operators are in charge for these.

In the assessment process the following are normally considered factors. 
1) Whether the supplier's products can meet the lowest technical requirement and the lowest standards.

2) Whether the quality of the supplier's products surpasses the customer's requirement and it is beneficial to the customer.

\section{Technical skill of the manufacture}

1) Whether the suppliers meet the national rules or commercial standards and the market classification.

2) R\&D and innovation ability in products

\section{The efficiency in manufacturing process, quality measurement, checking process and cost control system}

1) Whether there is the manufacturing and quality measurement for product samples.

2) Whether the suppliers stipulated the post-service policy.

3) Whether the suppliers supply the permanent technical support which includes the maintenance.

4) Whether the supplier possesses the certificate in quality assurance.

5) How the supplier supply the post-service in case there is no service-net locally.

6) Whether there are the complete product indications.

7) Whether the raw materials can be freely moved from storage to the workshop.

8) Whether there is the bottle-neck to the production.

9) Whether there are the branches for manufacturing plan and control. How do they operate?

10) Whether the company possesses the ability in multi-times manufacturing.

11) Does the feasibility depend on normal duty time or extra duty time?

6. Since the product quality depends on the manufacturing facilities and the process the buyers should also recognize the supplier standpoint to product quality through asking the following questions:

1) How do you think about the zero-fault ratio and the management throughout the manufacturing process?

2) Does your company possess the ISO9000:2000 certificate?

3) Do you have the statistics process control?

4) Do you make the sample trial and measurement before develop the new products?

5) Do you have the complete plan to assure the product quality?

6) How do you assess customer's satisfaction to your products?

7) Please describe company's principle for quality control.

8) Do you have the quality control handbook?

\section{Analysis of Company's Financial Situation}

Through the investigation of the company's financial situation the buyer can recognize the company's financial stability, financial capacity and the situation of earnings. Recognizing the company's capital-credit situation through the bank and other routes is necessary. The debt ratio should not be over $70 \%$ since too high debt ratio can be dangerous for bankruptcy.

\section{Organization and the Management of Human Resources}

It is also important in the survey that the buyer recognize the company's interior organizations, their operation, inter-support ability and the operation rules. The human resource office should supply the documents related to staff's number, structure of the staffs, staff's education background, staff's salary, normal working time, the training and the sex ratio. The buyer should also ask for the staff's rule handbook and the copy should be used for the check.

\section{Ability to Storage, Transport and Supply of Products}

In the survey the buyer should also recognize the supplier's ability in raw material storage, product storage and transportation and whether the ability can assure the long-time development of the company. There are also other questions such as whether the supplier can assure to supply the products in time and whether this largely depends on the JIT (Just in Time) system.

\section{Management Ability and Team Cooperation}

The following factors should be paid attention in the survey:

1) The high-rank staff's management level and their cooperation 
2) The high-middle-rank staff's attitude and stability

3) The competitive ability of the technicians and administrative staffs

4) Do the staffs possess cooperative and competitive ability and work in a harmonious environment?

5) Do the staffs pay attention on company's product quality and the improvement?

Are the staffs proud of their company?

\section{Company's Environment, Social Responsibility and Ability in Sustainable Development}

The factors related to workshop environment and sanitary facilities such as workshop temperature, air pollution, noise and workshop sanitary situation should be recognized in the survey. Satisfactory sanitary environment usually implies the high efficiency. Are there stipulated rules on human right such as restriction of non-adult employee, salary paying in time and assurance of holidays. Satisfactory environment can assure the staff's satisfaction and high quality products. The situation of the staffs and the company can reflect the supplier's management level.

12. The treatment of the wasted products and unused materials should be recognized. In the treatment the company should consider the environment pollution and abide by the relative rules.

\section{Historical Records (Company's Credit and Honesty)}

These mainly include the supplier's past operation such as tax paying, business operation, public reputation and customer's opinions.

\section{Company's Ability in IT Technology}

It's important to recognize the supplier's ability in operating the EDI and ERP system and efficiently employing the information communication such as linking the customers in manufacturing plans, product design, engineering data and product supplying date.

In addition to these the buyer should also consider the following factors such as whether the supplier agrees to accept the customer's suggestions in reforming the whole management system, the supplier's supplying and buying system and whether the company's high-rank staffs can communicate efficiently. The buyer can give the efficient evaluation to the supplier through tabular analysis for the above situation in order to select the satisfactory supplier finally.

\section{References}

Leenders, M.R., \& Fearon, H.E. Translated by Zhang, Jie \& Zhang, Qun. (2001). Purchasing and Supply Management. Mechanical Industry Publishing Company, Beijing.

Xiong, Shengxu. (2007). Enterprise Plan Management. Nanjing University Publishing Company, Nanjing. Yu , Miao. (2006). Supplier's Management. TsingHua University Publishing Company, Beijing. 